\title{
MISCELANEA
}

COMUNICACIÓN ORAL VII CONGRESO NACIONAL DE LA SOCIEDAD CIENTÍFICA ESPAÑOLA DE ENFERMERÍA - SCELE. Mayo de 2014. UNIVERSIDAD DE ALICANTE.

\section{LA SEXUALIDAD COMO VARIABLE IMPORTANTE EN LA CALIDAD DE VIDA(C.V) DE LAS PERSONAS CON DISCAPACIDAD}

Esther Sánchez Raja ${ }^{1}$; María Honrubia Pérez²

\author{
1. ASAD, Serveis Sanitaris. \\ 2. Universidad de Barcelona.
}

CORREO ELECTRÓNICO: esanchezra@gmail.com mhonrubia@ub.edu 


\section{PALABRAS CLAVE:}

Sexuality, Quality of Life, Disability, Nursing

La afectividad y la sexualidad se han de desarrollar adecuadamente en los individuos aunque no estén en plenas condiciones físicas y psíquicas, indiferentemente si residen en su domicilio o en un centro especializado. La atención a la discapacidad no siempre ha estado ligada al concepto de cuidados de enfermería, pero en la actualidad se considera indispensable hacerlo desde la defensa de los derechos de las personas con Diversidad Funcional (D.F.), ratificados en la Convención de Ginebra de 2008. En este trabajo se presentan datos que forma parte de una tesis doctoral en la que se estudia las alteraciones de la sexualidad en personas con D.F. y como ésta influye en su calidad de vida (CV); Planteado desde el marco enfermero de los Patrones Funcionales de Marjory Gordon, por visualizar los procesos vitales siempre desde una visión integral de salud, guiando de forma lógica al diagnóstico enfermero, contemplando al paciente desde una visión holística y recogiendo toda la información necesaria del paciente, familia y entorno incluyendo su sexualidad.

\section{Objetivo General:}

- Describir y comprender las alteraciones que se producen en la sexualidad de las personas con D.F. y como éstas pueden afectar la C.V.

\section{Objetivos Específicos:}

- Conocer desde la perspectiva de las personas afectadas las repercusiones de la D.F. en sus relaciones interpersonales.

- Identificar el papel que juegan los profesionales sanitarios, especialmente los profesionales de enfermería, en la educación afectiva sexual de las personas con D.F.

- Generar conocimiento fundamentado en referencia a la repercusión que tienen las alteraciones sexuales en la C.V.

\section{Metodología:}

Diseño metodológico cualitativo, aplicando la Etnografía Enfocada.

Sujetos de estudio: Personas con D.F. que están inscritos en la Asociación de Daño cerebral ATENEO Castellón.

Criterios de inclusión: Personas asociadas con D.F. en edades comprendidas entre 19 y 60 años, cuyo nivel cognitivo permita la participación en un grupo focal.

Consideraciones éticas: Se solicita la aprobación de la comisión de ética de la Universidad de Barcelona. A todos los informantes se les informó sobre sus características, los objetivos, del tratamiento de la información, así como de los mecanismos de confidencialidad para asegurar el anonimato de los participantes, consentimiento informado por escrito de la Asociación y de los participantes.

Recolección de datos:El trabajo de campo se realizó entre el 12 de Febrero y el 29 de Mayo de 2013. La muestra estuvo conformada por el total de personas que cumplían los criterios de inclusión 23 varones y 5 mujeres con D.F. que fueron repartidos en tres grupos focales. En cada grupo focal se seleccionaron informantes que abarcaron la tipología de pacientes en relación con el sexo, edad.

\section{Resultados:}

Las categorías que se derivan de la información son en referencia a:

1. Cambios generados en su C.V.: la totalidad de componentes expresan que el padecer una D.F. ha cambiado un $100 \%$ sus vidas, sobre todo aquellos que su discapacidad es producida por una lesión adquirida a la edad adulta; La mayoría comentan que la D.F. ha influido de forma negativa en sus vidas; Todos los pacientes comentan una disminución en su calidad de vida. 
2. Cambios en sus relaciones sociales: Las personas que padecen una D.F. se encuentran a menudo en una situación de aislamiento, suelen tener menos amigos y contactos sociales, el padecer una disminución de autonomía física y disminución de capacidad psíquica, les impide participar en muchas actividades sociales.

3. Cambios en su vida laboral: Los entrevistados, indican no tener oportunidades laborales, y cobran en su mayoría una pensión de invalidez.

4. Cambios generados en su sexualidad: Todos los participantes de los grupos focales refieren cambios muy significativos en su Sexualidad, sobre todos los que la D.F. no es desde el nacimiento; Ninguno de los participantes comenta estar satisfecho con su sexualidad actual; La mayoría de los varones incluidos los que tienen pareja estable, practican la masturbación con frecuencia, algunos usuario que no conviven en pareja, no están tutelados y disponen de poder adquisitivo utilizan con frecuencia los servicios de asistentes sexuales.

5. Información en sexualidad por parte de los profesionales (Enfermería): Todos los usuarios participantes en el estudio comentan que no han recibido información al respecto y que han echado de menos el recibir una educación sexual adecuada a sus necesidades.

\section{Conclusiones:}

Los informantes que participan en el estudio cualitativo, refieren en su totalidad y dándose una saturación de datos, que las alteraciones sexuales debidas a padecer una D.F. son percibidas sobre todo por los que las han adquirido posterior al nacimiento, como un cambio radical en su estilo de vida y la valoran como un ítem importante a tener en cuenta en su C.V., hasta el punto de mencionar que ésta ha cambiado un $100 \%$; La totalidad de informantes (varones y mujeres) refieren cambios generados en las practicas sexuales y en las diferentes dimensiones de la sexualidad: Deseo, Excitación, Orgasmo. 